\title{
Concomitant radiofrequency Maze III - procedure and surgical ASD closure in adults
}

\author{
OS Golovenko ${ }^{1 *}$, W Lazoryshynets ${ }^{1}$, VP Zalevskiy ${ }^{2}$, BB Kravchuk², W Sakalov ${ }^{1}$, IA Perepeka ${ }^{1}$, MM Rudenko ${ }^{1}$, \\ KV Rudenko ${ }^{3}$, OZ Paratsiy ${ }^{2}$, YP Truba ${ }^{1}$ \\ From 23rd World Congress of the World Society of Cardio-Thoracic Surgeons \\ Split, Croatia. 12-15 September 2013
}

\section{Background}

Atrial fibrillation (AF) and others supraventricular arrhythmias are one of the most frequent preoperatively complications in adult patients with ASD. We present our experiences of surgical treatment of AF with ASD in adults.

\section{Methods}

84 adult patients (mean age 40,8 \pm 7,2 years) with ASD and different forms of AF were operated between 20052012 with next forms of AF: paroxysmal - 48, persistent - 26, long persistent - 10 patients. We performed radiofrequency "maze III" procedure and then ASD closure in CPB. Mean CPB-time was $64 \pm 18 \mathrm{~min}$. Lines of ablation were performed point-by-point applications with exposition of 15 seconds. All patients were on amyodaron-therapy for the first three months. The follow-up period was from 24 to 36 months. Standard 12-lead ECG was done daily during the postoperative hospital stay and at $1,3,6$, and 12 months postoperatively. To evaluate cardiac function and the recovery of the atrial contraction TTE was performed before discharge and at 3, 6, and 12 months postoperatively.

\section{Results}

At 6 months follow-up sinus or atrial rhythm was present in $73(86.9 \%)$ patients. 53(63,1\%) patients have no need of antiarrhythmic therapy. Right atrial contractility was restored in $100 \%(84 / 84)$ and left atrial contractility in $67.9 \%(57 / 84)$ of patients. LVEF was increased from $0.43 \pm 0.02$ to $0.52 \pm 0.10(\mathrm{P}<0.05)$. In 3 cases $(3.6 \%)$ sinus node dysfunction was developed and needed permanent cardiac pacing (AAIR mode).

\section{Conclusions}

The main hemodynamic factor in patients after "Maze III" procedure is preservation of AV-synchrony. The maintaining sinus rhythm and AV-synchrony is more important, than restoration of atrial systolic function. The mean LVEF increased in postop period. Independent risk factors for late $\mathrm{AF}$ recurrence were longer duration of AF ( $>60$ months) $(\mathrm{OR}=2.721, \mathrm{p}=0.025)$, increased left atrial size $(\mathrm{OR}=1.105, \mathrm{p}=0.004)$. Duration of AF is predisposable factor for sinus node dysfunction development.

\section{Authors' details}

${ }^{1}$ Department of Congenital Heart Defects Surgery, Amosov National Institute of Cardiovascular Surgery, Kyiv, Ukraine. ${ }^{2}$ Department of Electrophysiology,

Amosov National Institute of Cardiovascular Surgery, Kyiv, Ukraine.

${ }^{3}$ Department of Myocardial Pathology, Amosov National Institute of

Cardiovascular Surgery, Kyiv, Ukraine.

Published: 11 September 2013

doi:10.1186/1749-8090-8-S1-P53

Cite this article as: Golovenko et al.: Concomitant radiofrequency

Maze III - procedure and surgical ASD closure in adults. Journal of

Cardiothoracic Surgery 2013 8(Suppl 1):P53.

\footnotetext{
* Correspondence: dr.golovenko@gmail.com

'Department of Congenital Heart Defects Surgery, Amosov National Institute of Cardiovascular Surgery, Kyiv, Ukraine

Full list of author information is available at the end of the article
} 